\title{
Mons. Alonso Llanes y Argüelles, Arzobispo de Sevilla (1783-1795)
}

\author{
Juan Pablo Domínguez Teba \\ Licenciado en Teología y en Historia de la Iglesia
}

\begin{abstract}
Resumen: En este trabajo abordamos la trayectoria eclesiástica de Llanes y Arguelles, deteniéndonos, sobre todo, en el periodo de su pontificado como arzobispo de Sevilla. El trabajo está dividido en tres partes. Comenzamos abordando su origen familiar, formación y su etapa como obispo de Segovia. A continuación, presentamos el transcurso de los dos sexenios como arzobispo hispalense (1783-1789 y 1789-1795). Luego, dedicamos un apartado a las empresas artísticas de Llanes y Arguelles como arzobispo de Sevilla. Finalmente, añadimos un apéndice documental. Este estudio además de arrojar luz sobre su pontificado, es una reflexión que manifiesta el ideal de una verdadera reforma eclesial, en el contexto de unas perspectivas históricas de cambio como las que se sucedieron durante la Ilustración española, teniendo como referencia la condición de obispo Pastor que da la vida por sus ovejas, como refleja la trayectoria eclesiástica de Llanes y Arguelles.
\end{abstract}

\begin{abstract}
We study in this paper the clerical career of Llanes y Arguelles, focusing it mainly on his period as Archbishop of Seville. The paper is divided into two parts. We start talking about his family years, training and stage at Bishop of Segovia. Then, we offer two big blocks referred to his period as Archbishop of Seville, divided into two periods of six years (1783-1789; and 1789-1795). Later, we dedicated a section to his artistic decisions and a final appendix with several documents. This paper is more than a simple theoretical research about a bishop in a specific diocese: it is a reflection about the ideal of a real clerical reform, within the context of changing perspectives as the ones that happened during the Spanish Illustration, taking into account the model of a bishop as a shepherd that is able to die for his sheep, as it was developed during the clerical career of Llanes y Arguelles.
\end{abstract}




\section{FAMILIA, FORMACIÓN Y EPISCOPADO EN SEGOVIA}

\subsection{El linaje de Llanes y el señorío de Campomanes}

Alonso Marcos de Llanes y Arguelles nació en el palacio de Rebollín de Santa María de Noreña, un pueblo del principado de Asturias, el 26 de abril de 1732. Procedía de una familia noble. Fue hijo de Menendo de Llanes Campomanes, caballero de Santiago y regidor perpetuo del concejo de Lena ${ }^{1}$ y de María Teresa Argüelles Cienfuegos. Ambos fueron personas muy esclarecidas del principado.

Las pruebas de acceso de Llanes al cabildo catedral de Sevilla como doctoral en 1766 muestran su noble origen familiar. Estas pruebas revelan la vinculación del futuro arzobispo de Sevilla con los marqueses de Ferreras y Camposagrado. Señores de Campomanes, uno de los antepasados ilustres fue Don Fernando Valdés, arzobispo de Sevilla (1547-1566), que también fue Presidente del Consejo de Castilla durante los reinados de Carlos I de España y Felipe II².

Por vía paterna, tenía vínculos con fray Juan de la Anunciación, general de los Carmelitas Descalzos y escritor del siglo XVII. También estaba emparentado con Melchor de Llanes, gobernador de Mérida y teniente en Pamplona, y Toribio de Cienfuegos, que fue Capellán de honor del rey, prior de San Marcos de León y abad de Arbás. Ambos fueron tíos del eclesiástico.

Por vía materna, entroncaba con los marqueses de Santa Cruz de Marcedano. Hay indicios de que estuvo relacionado con Gutiérrez Arguelles, auditor de la Rota, con Antonio Arguelles, presidente del Consejo de Castilla. Encontramos también entre sus ancestros a Pedro y Francisco Arguelles, deanes de las iglesias de Santiago y de Oviedo, a Pedro Cienfuegos, obispo de Popayán y Trujillo, y a José Cienfuegos, inquisidor de México, de Valladolid y tesorero de Sevilla.

Según el profesor Justo García, Alonso de Llanes tuvo cinco hermanos. El mayor, José Antonio, participó en el sínodo ovetense de $1769^{3}$. Casado con Teresa Cienfuegos, fue procurador general del principado de Asturias hasta su fallecimiento (1775). Siendo por entonces Alonso de Llanes obispo de Segovia, medió para que sus sobrinas ingresaran en las Descalzas Reales de Madrid y de Segovia. También se ocupó de su hermano Francisco y de su sobrino Rodrigo, arcedianos de Écija y de Sevilla. Tal vez, el familiar que alcanzó mayor celebridad fue su sobrino Francisco Javier Cienfuegos y Jovellanos, titular de la mitra hispalense (1824-1847) después de haber sido obispo de Cádiz (1819-1824) .

1 Vid, M. Lasso de la Vega y López de Tejada Saltillo, Linajes y palacios ovetenses: datos para su historia, Madrid 1992, 131-140.

2 Vid, M. Martin Riego - C.L. Ladero Fernández, «Arzobispos y caridad en la Iglesia de Sevilla (1755-1799)» en Anuario de historia de la Iglesia andaluza 7 (2014) 13-16.

3 Cfr, J. García Sánchez, El sínodo Diocesano de Oviedo de 1769, Oviedo 1999, 35-37.

4 Vid, J. Matute Gavira, Anales eclesiásticos y seculares de la muy noble y muy leal ciudad de Sevilla, III, Sevilla 1887, 152-156. 


\subsection{Formación intelectual: Doctorado en leyes y cánones}

Aunque no hay muchos datos sobre la formación intelectual del obispo Llanes y Arguelles, sabemos no obstante que cumplía los requisitos indicados por el rey Felipe II en la Instrucción de $1588^{5}$. Su formación en Salamanca y Valladolid obedeció a la mencionada normativa real.

El doctor Barrio Gozalo, se refiere al nivel de exigencia cultural que debían tener los prelados. Así, el 60,6\% de los prelados modernos obtuvieron el grado de doctor, el 18,1\% el de licenciatura y el 1,6\% el de bachiller ${ }^{6}$.

En el caso de Llanes nos encontramos ante un eclesiástico formado en su infancia por el bachiller Ignacio Mere, catedrático de filosofía de la universidad de Oviedo ${ }^{7}$. En sus años jóvenes consiguió el grado de bachiller en leyes y cánones en la universidad del Principado, donde permaneció dos años como catedrático de teología ${ }^{8}$. Posteriormente, estudió en el colegio mayor San Pelayo de Salamanca, donde fue juez de estudios y catedrático de cánones. La Universidad de Salamanca sería su última etapa antes de ingresar en el Colegio Mayor de Santa Cruz, en Valladolid. El 17 de septiembre de 1755, se graduó como doctor en leyes y cánones por la universidad de Ávila9.

Mons. Llanes, a diferencia de la mayoría de los obispos andaluces de su tiempo, más inclinados al estudio de la teología, tuvo una formación eminentemente jurídica. En este sentido, es un caso singular. El tratadista Giordanini, ya había juzgado a principios de siglo que los estudios de derecho civil eran impropios de la dignidad episcopal ${ }^{10}$. Otros, como Alessandro Sperelli, obispo de Gubio (s. XVII), valoraban positivamente que los prelados estuvieran instruidos en historia, oratoria y elocuencia, para transmitir mejor, de este modo, su doctrina ${ }^{11}$.

Giovanni Battista Rinuccini, otro tratadista del periodo, valora el conocimiento de textos clásicos profanos en la formación de los clérigos. Battista Braschi, por su parte, tiene una aproximación al arte y a la poesía muy novedosa, cuando afirma que es bueno para los sacerdotes el conocimiento de la poesía, la historia civil, incluso la comedia ${ }^{12}$. Giovanni Botero sugiere como soporte de la piedad las distintas realizaciones artísticas, tales como la escultura, la pintura o la arquitectura ${ }^{13}$.

\footnotetext{
5 Cfr, A. Ferrer de Valdecebro, La vara vigilante, Madrid 1659, 29.

6 Cfr, M. Barrio Gozalo, «Sociología del alto clero en la España del siglo Ilustrado», en Revista d'història moderna 20 ( 2002) 44.

7 Cfr, J. Alonso Morgado, Prelados sevillanos, 682.

8 Vid, F. Canellas Secades, Historia de la universidad de Oviedo y noticias de los establecimientos de enseñanza de sus distrito (Asturias y León), Oviedo 1995, 105-110.

9 Cfr, J. Alonso Morgado, Prelados sevillanos, 699.

10 Cfr, L. MedrazzI, «L'ideal pastorale del vescovo nel primo settecento», en Extractum ex Divus Thomas 3 (1971) 361.

11 Vid, A. SPERELLI, Il vescovo, Roma 1655, 58-64.

12 G, B, Rinuccini, Della dignitá et officio dei vescovi, Roma 1651, 146.

13 Cfr, G. Botero Benese, Dell'Officio del Cardinale, Viterbo 1702, 5.
} 
El obispo Llanes debió tener ciertamente una sólida formación académica. De ello da testimonio la oración fúnebre compuesta por el P. José Ramírez, franciscano, a su muerte:

"¡Qué decoro, sencillez, y verdad señalan los pasos jóvenes del Señor Llanes, ya cultive su espíritu, ya regle su corazón! Cultivando su entendimiento fue uno de aquellos estudiantes, no muchos en el siglo de las Luces y reforma de las escuelas, que a los progresos de la razón y del talento juntan los aumentos de la religión y de la piedad. Gramático, retórico, filósofo, canonista, por la más seria y constante aplicación, que aún en la edad pueril oprimida casi siempre del sueño, le hacía tomar luz artificial y pasar las vigilias de noche y de madrugada sobre los libros, no por esto dejó de estudiar con más esmero el santo temor de Dios y ponerlo por principio de sus tareas literarias" ${ }^{\prime 14}$.

Llama la atención que Antonio Despuig, su sucesor en la sede hispalense, tuviera una formación análoga. Cursó humanidades en el colegio de Montesión de Palma de Mallorca, antes de estudiar filosofía y derecho en su universidad, donde alcanzó el doctorado en cánones ${ }^{15}$.

\subsection{El contencioso de la colegiata de Olivares}

En el año 1762, Llanes recibió el orden del presbiterado. En los años siguientes su carrera eclesiástica tuvo como hito la designación como canónigo doctoral de Palencia y posteriormente, como doctoral de Sevilla.

Un aspecto interesante de la trayectoria de nuestro obispo fue la intensa actividad que desarrolló en la Corte. Un asunto exigió su empeño durante mucho tiempo. Se trataba del problemático cobro de los diezmos de la abadía de Olivares. Fundada en el siglo XVII por el Conde-duque de Olivares, había llegado a convertirse en un caso notablemente irregular. Su capítulo había adquirido unos privilegios que ponían en discusión la autoridad del arzobispo sevillano $^{16}$. Mons. Llanes consiguió, después de muchos esfuerzos, resolver dicha irregularidad.

\subsection{Nombramiento de Llanes como obispo de Segovia (6-VI-1774)}

El prestigio que Llanes había adquirido en la Corte hizo posible que Carlos III lo considerara a la hora de proveer la Iglesia de Segovia ${ }^{17}$. Los inicios de su pontificado se caracterizaron por su actividad caritativa, que desarrolló

14 Cfr, J. Ramírez, Sermón fúnebre del Excmo e Ilm. Señor Don Alonso Marcos de Llanes, Imprenta de Félix de la Puerta, Sevilla 1795, 18.

15 Cfr, J. Salvá, El Cardenal Despuig, Palma de Mallorca 1964, 27-28.

16 Vid, F. Amores Martínez, La colegiata de Olivares, Sevilla 2001, 134-139.

17 Cfr, M. Barrio Gozalo, «La jerarquía eclesiástica en la España moderna. Sociología de una élite de poder (1556-1834)» en Cuadernos de historia moderna 25 (2000) 40. 
en tal grado que dotó de una asignación anual de 80 fanegas de trigo a varias comunidades religiosas de la ciudad ${ }^{18}$. Cuando Llanes fue nombrado obispo de Segovia tenía 42 años de edad.

\subsection{Fundación del Seminario Conciliar en 1781}

Mons. Llanes visitó personalmente todos los pueblos de la diócesis, predicando, acompañando a los misioneros que le seguían en sus trabajos apostólicos y socorriendo toda clase de necesidades. Con ocasión del Jubileo del Año Santo de 1776, concedido por Pío VI, publicó una exhortación pastoral para los vicarios, curas párrocos, confesores, predicadores y fieles del obispado segoviano.

Como obispo de Segovia, se dedicó por completo a la mejora material e intelectual del clero. Para ello, erigió en 1781 un seminario conciliar, cuyas constituciones y plan de estudios elaboró ${ }^{19}$. Lo dedicó a San Frutos, patrón de la diócesis y a San Ildefonso. El mencionado seminario se estableció en una antigua propiedad de los jesuitas. La Compañía de Jesús llegó a la ciudad el 20 de febrero de 1559, donde edificaron un colegio y un templo. Del primero se encargó el arquitecto italiano Giuseppe Valeriano (1557), y del segundo, Juan de Mugaguren, cuyo estilo parece anticipar la clerecía de Salamanca.

Tras la expulsión de los jesuitas por la Pragmática Sanción de Carlos III, el colegio pasaría a tener una doble utilidad. Una parte se destinó a clases de primeras letras, humanidades y retórica; la otra sección se convirtió en Seminario conciliar $^{20}$. Llanes estableció en él una selecta biblioteca el 18 de junio de 1781.

El prelado segoviano, además, aprobó en 1783 el Plan de Reforma Beneficial o de Curatos. Se fijaba la congrua de los curas de la ciudad segoviana en 5000 reales anuales, en 4000 la de los curas rurales, y en 3500 la de los vicarios perpetuos. Para título de ordenación fijó la congrua en 1100 reales al año.

\subsection{Carta pastoral de despedida: herencia y promesa}

Llanes permaneció en la diócesis castellana durante nueve años, hasta su traslado a Sevilla en 1783. En su despedida, escribió una extensa carta pastoral, en la que animaba al pueblo y al clero segoviano a no desistir en la reforma de las costumbres, además de disculparse de los posibles errores que hubiese cometido. Publicamos, a continuación un extracto de dicha carta pastoral:

18 Vid, M. Barrio Gozalo, «Perfil socio-económico de una élite de poder de la Corona de Aragón. Los obispos del reino de Aragón (1536-1834)» en Anthologica annua, 43 (1996) 34-36.

19 Vid, M. Barrio Gozalo, Estudio socioeconómico de la Iglesia de Segovia en el siglo XVIII, Segovia 1982, 811-816.

20 Cfr, J. García Hernando, «El seminario conciliar de Segovia, antecedentes históricos» en Estudios Segovianos, 11 (1959) 31-32. 
“Esta consideración me hace menor el desconsuelo al separarme y despedirme de aquellos miembros con quienes componía un cuerpo mystico en lo espiritual de esta Diócesis, y sí me aflige el temor, que habiéndose servido S. M. (Dios le guarde) nombrarme para la iglesia y arzobispado de Sevilla, tanto mayor que mis méritos y tan superior a mis fuerzas, ¿cómo podré imitar, ni menos desempeñar un ministerio y cargo que miraban como insoportable los Leandros, los Isidoros y otros santos prelados?"21.

\section{MONS. LLANES, ARZOBISPO DE SEVILLA: PRIMER SEXENIO (1783-1789)}

\subsection{Nombramiento (2-VI-1783)}

Llanes tenía 51 años de edad cuando accedió a la mitra isidoriana, con una amplia experiencia en la diócesis de Segovia. ${ }^{22}$ Su afinidad con la política regalista le valió el apoyo de la Corona para ocupar la sede hispalense. Le precedía otro candidato, Pedro Quevedo y Quintano, obispo de Orense, que no aceptó, pese a ser elegido por el monarca. De este modo, Llanes, canónigo doctoral de Sevilla, sería preconizado arzobispo. Llanes aceptaba el nombramiento el 8 de octubre de 1783, apoyado por el Conde de Campomanes ${ }^{23}$.

Además de Campomanes, en la designación de nuestro obispo para la sede hispalense intervinieron otras personalidades. Antonio Meyán de Morla, abad de la colegiata de Jerez, señalaba la importancia de la intercesión de José Fernández de Miranda, duque de Losada. Llanes da cuenta de su nombramiento al cabildo de Sevilla (2 XI 1783). Tomaría posesión de la sede isidoriana el 26 de mayo de 1784.

\subsection{Estudio sobre la erección de Jerez como sede episcopal}

Antes de su venida a Sevilla, hubo un movimiento en Jerez de la Frontera para erigirse en catedral episcopal. Fueron enviadas al rey dos representaciones (18 de julio y 8 de noviembre de 1783). En ellas se quería demostrar que Jerez era la antigua diócesis de Asidonia. Llanes encargó a Cevallos un estudio sobre esta particular $^{24}$, que dio como resultado la plausibilidad de que Jerez de la Frontera volviera a ser una sede episcopal ${ }^{25}$.

21 Vid, A.M. Llanes y Arguelles, Pastoral del ilustrísimo señor Don Alonso Marcos de Llanes (...) en que explica los motivos y medios para que los fieles tributen a Dios las gracias por los prósperos sucesos de la monarquía, Segovia 1784, 18-30.

22 Vid, M. Barrio Gozalo, «Perfil socio-económico de una élite de poder de la Corona de Aragón» 167-172.

23 Cfr, A. Astorgano Abajo, Don Juan Meléndez Valdés. El ilustrado, Badajoz 2007, 129.

24 Cfr, V. Gean - F.A. García Romero, «Origen e historia del antiguo obispado asidonense» en Isidorianum 2 (1992) 16-17.

25 Un siglo más tarde, este estudio fue publicado en forma de libro, titulado La Sidonia Bética Autor del libro (Sevilla, 1864). En él se demostraba que Jerez no fue nunca la antigua Asido, capital del obispado Asidonense, ni sede episcopal, y que la sede asidonense fue trasladada a Cádiz en 1266. No obstante, actualmente, el obispado de Jerez de la Frontera, erigido por la 


\subsection{Acción pastoral de Llanes fuera de la archidiócesis}

Llanes se ausentó de la archidiócesis cuando se desplazó a Madrid, para consagrar a Antonio Andrés López Arroyo como obispo de Astorga (15 XII 1783) ${ }^{26}$. En dicha ocasión, fue acompañado por Francisco Mateo Aguiriano Gómez, obispo titular de Tagaste y auxiliar de Toledo, y por Felipe Pérez Santa María, titular de Constantia de Arabia y auxiliar de Toledo.

En otros momentos, nuestro obispo también tuvo que ausentarse. Por ejemplo, en la visita ad limina, realizada por el arzobispo en 1791, informa a Pío VI de la precariedad en la que se encontraban los sacerdotes de la diócesis, después de la aplicación del Plan de Curatos.

\subsection{Solicitud por el clero: ejercicios espirituales para sacerdotes}

Nuestro prelado convocó, a puerta cerrada, a los clérigos menores y a los sacerdotes de la ciudad en el convento del Espíritu Santo, al objeto de que realizaran unos ejercicios espirituales. Llanes mantuvo una estrecha relación con este convento, al que acudía en numerosas ocasiones para retiros con sacerdotes. Dichos ejercicios fueron predicados por Fray Diego José de Cádiz OFMC, desde el 16 al 20 de diciembre de 1784. El arzobispo participó en el retiro.

Con su participación en estos ejercicios, Llanes daba ejemplo a todos de su piedad, devoción y de sus fundadas esperanzas respecto a su acertado gobierno y a su preocupación por la formación de los sacerdotes ${ }^{27}$. El capuchino además de alentar a los sacerdotes a llevar una vida de piedad, criticó las injerencias de la monarquía en los bienes eclesiásticos. Esto no era la primera vez que fray Diego José de Cádiz hablaba en este sentido. Ya en 1786 en unos ejercicios espirituales que predicó en el seminario de San Carlos de Zaragoza, atacó las opiniones de Lorenzo Normante y Carcavilla, catedrático de Economía Civil creada por la Real Sociedad Económica de Amigos del País.

\subsection{Controversias con el Conde de Campomanes}

\subsubsection{Intentos de fundación de un Seminario Conciliar}

El 10 de octubre de 1786 el arzobispo escribe una larga carta a Campomanes desde Sanlúcar de Barrameda, donde traza la idea de fundar un seminario conciliar igual que había hecho en Segovia, obedeciendo a las disposiciones del

bula papal Archiepiscopus hispalensis, del 3 de marzo de 1980, y que se dirige espiritualmente a los cristianos de la zona norte de la provincia de Cádiz, lleva el título de asidonense-jerezano para recordar de forma permanente aquel obispado antiguo del que ciertamente esta zona formada parte.

26 Cfr, A. Fernández Collado, Obispos de la provincia de Toledo (1500-2000), Toledo 2000, 148.

27 Cfr, J. Alonso Morgado, Prelados sevillanos, 702. 
Concilio de Trento. Lamentaba que la diócesis hispalense todavía no lo tuviera. El arzobispo llegaba a decir:

"Por raros incidentes, tiene la desgracia de que quedasen frustrados los deseos de sus antecesores, que procuraron según sus fuerzas, no sólo erigir el Seminario, sino adelantarle, destinando a sus expensas casas y rentas con las que se mantuvo cierto número de colegiales" 28 .

El arzobispo se quejaba también, de que el Colegio de las Becas, destinado a la formación de los seminaristas, y de que todas las rentas, la iglesia, los altares y los colegios que son regidos por los jesuitas, hubieran sido absorbidos en las temporalidades. El Colegio de las Becas era propiedad de la mitra, pero se perdió porque fueron concedidas a la universidad de Sevilla ${ }^{29}$. Su venta ascendió a más de dos millones y medio de reales, sin incluir la biblioteca. El arzobispo concluye su carta exclamando: "Todo lo ha perdido la mitra, esta Ciudad y el arzobispado" ${ }^{30}$.

Más adelante solicitaría el colegio de San Hermenegildo, que había pertenecido en su tiempo a la Compañía, para establecer en él el seminario conciliar, pero a la postre se ocuparía en otros menesteres. El arzobispo tenía preparados diez millones de reales para costear las obras del seminario. Sin embargo, Llanes no lograría verlo, aunque dejó dicha cantidad para que su sucesor llevase a feliz término este proyecto $^{31}$.

\subsubsection{Críticas contra la Real Hacienda}

Llanes enfatizó su interés por arremeter contra todo tipo de escándalos y transgresiones que supusieran un grave desacato contra los bienes eclesiásticos. Siguiendo el ejemplo de fray Diego José de Cádiz, el 7 de diciembre de 1787, el arzobispo exhortó a los clérigos al cumplimiento de las obligaciones de pagar las contribuciones estatales. Pero, también pedía a la autoridad real que prohibiera comerciar con los bienes eclesiásticos, dado que dicha actividad era pecado de simonía.

Las críticas del arzobispo a los escándalos y delitos cometidos por la Real Hacienda que perjudicaban a los grupos sociales más pobres, provocó la respuesta del conde de Floridablanca que escribió a Llanes manifestando el malestar del rey. Era evidente que el arzobispo al criticar al estado ponía en tela de juicio la autoridad regia, y ello no podía pasar desapercibido por la corte.

\footnotetext{
Cfr, C. Ros Carballar, Los Arzobispos de Sevilla, 226.

Vid, F. Aguilar Piñal, Historia de Sevilla en el siglo XVIII, 267-272.

Vid, C. Ros Carballar, Los Arzobispos de Sevilla, 227-229.

Cfr, J. Alonso Morgado, Prelados sevillanos, 711.
} 


\section{MONS. LLANES, ARZOBISPO DE SEVILLA: SEGUNDO SEXENIO (1783-1789)}

\subsection{Influjo de la espiritualidad de Llanes en el gobierno episcopal}

La trayectoria espiritual de Llanes se caracterizó por la importancia que le concedió siempre a la oración. También mostró un gran interés por las devociones particulares, destacando su afinidad al culto tributado al Santísimo Sacramento ${ }^{32}$. Visitaba diariamente al Santísimo durante el Jubileo circular de las Cuarenta horas que él mismo había convocado para todos los sacerdotes y fieles de la archidiócesis ${ }^{33}$.

En 1791, el contador del ayuntamiento de Sevilla, Juan José Díez de Bulnes, funda para Sevilla la Real Congregación de Luz y Vela, para dar culto al Santísimo, constituyéndose el arzobispo en su principal impulsor ${ }^{34}$.

Siendo informado acerca del hecho de que en las iglesias del Real Patronato de Madrid, había sido erigida otra congregación con igual objeto que aquella de la Real Congregación de Luz yVela fundada por el alcalde de Sevilla, el arzobispo Llanes fue incorporado a ella el ocho de marzo de 1792.

En 1793 mandó a todos los curas y vicarios de la archidiócesis que procurasen en sus respectivas parroquias promover el culto al Santísimo Sacramento por medio de la continua oración, recomendada por la Real Congregación de la Corte, que no llegó a prosperar, siendo así que la de Sevilla ofrecía el más digno ejemplo de constancia ${ }^{35}$.

Antonio de Vargas, canónigo y rector de la universidad de Sevilla, en su oración fúnebre dice refiriéndose a Llanes:

“¿Con quanta edificación y reverencia se postra ante Jesu-Christo Sacramentado, a quien visita diariamente en el Jubileo circular? Es el primero que toma en sus manos el cirio, y hace oración en el día en que da principio a su exercicios devotos la congregación de Luz y Vela. Exercicio que protege, devoción que promueve y recomienda a sus diocesanos en una circular muy edificante ${ }^{\prime \prime 36}$.

\subsection{Principales programas de reforma}

\subsubsection{Mejora del nivel intelectual del clero: Normativa sobre las conferencias morales}

El arzobispo Llanes llevó a cabo una amplia reforma en la archidiócesis de Sevilla trabajando de cara a la mejora del nivel intelectual del clero ${ }^{37}$. En esta

32 Cfr, C. LAdERO FERnÁNDEZ - M. MARTíN, «Arzobispos y caridad», 45.

33 Cfr, M. MARTIN RieGO, «La Eucaristía en la archidiócesis hispalense a través de los libros de visitas pastorales. Siglo XVIII» en Isidorianum 3 (1993) 208.

34 Cfr, F. Aguilar PIÑal, Impresos sevillanos del siglo XVIII, Madrid 1974, 194.

35 Cfr, J. Matute Gaviria, Anales eclesiásticos y seculares, 124.

36 Cfr, A. Vargas, Oración fúnebre que en las exequias que hicieron por el Excm. Señor Don Alonso Marcos de Llanes y Arguelles, arzobispo de Sevilla, el día 28 de abril de 1795, Sevilla 1795, 19.

37 Vid, M. MARTín RIEGO, «Las conferencias morales y la formación permanente del clero hispalense en el siglo XVIII. El modelo de Écija (1785-1800)» en Isidorianum 7 (1995) 167-248. 
línea hemos de colocar el restablecimiento de las conferencias morales como mejor remedio para erradicar la ignorancia en el clero. En su carta de despedida de la diócesis castellana, el obispo de Segovia y electo arzobispo de Sevilla, insiste en la necesidad de formación para los sacerdotes y recomienda la asistencia a las conferencias morales:

"Bien sé que no hay necesidad de preveniros que el estudio y la ciencia son indispensables a los sacerdotes y especialmente a los párrocos. No malogréis por el amor de Jesucristo los talentos de que Dios os ha de pedir la más estrecha cuenta. No incurráis en el borrón más feo de vuestro carácter, que es la ignorancia... y así no dejéis de asistir a las conferencias morales tan útiles y recomendadas por mis predecesores y tan religiosamente observadas en estos reinos y otros católicos dominios... dadme el gozo y consuelo de instruiros más y más para cumplir con vuestro ministerio. Poned a este fin tan importante todo vuestro cuidado y, así renovaréis el amor al estudio y desempeñaréis vuestra obligación" ${ }^{\prime 38}$.

Una vez instalado en la diócesis hispalense y, conocida la realidad de la misma a través de las visitas pastorales, restablece las conferencias morales con unas reglas muy concretas, recogidas en una circular, fechada el 4 de marzo de 1785. En esta circular, que está dividida en dos partes, alude a la necesidad de estas conferencias y a la obligación que tienen los clérigos de asistir a ellas:

"A pesar de que, por la injuria de los tiempos se halla por lo común desatendido y solamente observado de algunos celosos vicarios y curas que han manifestado el más cumplido desempeño de sus obligaciones" ${ }^{\prime 39}$.

En la misma circular ordena a los vicarios que convoquen al clero para restablecer las conferencias morales:

"En cuya atención mandamos, que luego que reciba Vmd, esta convoque el clero de esta parroquia, y estando junto se la lea, y también las reglas que se han de observar en las conferencias morales, y acompañan a ésta, y desde luego trate de restablecerlas, según el orden que va propuesto, dando principio el lunes inmediato, presidiendo las dichas conferencias por sí mismo, o estando legítimamente impedido por el que le siga, procurando que en todo el año se traten y conferencien las principales materias de teología moral práctica, en orden a la administración de los sacramentos, sin permitir disputas y altercaciones molestas, intimando se observe la mayor compostura, cual corresponde al carácter y circunstancias de Ministros del Santuario" ${ }^{\prime 4}$.

38 Carta pastoral de Alonso Marcos Llanes y Arguelles: Aparece dividida en 2 partes, estando la segunda dedicada por completo a invitar a los párrocos, sacerdotes, predicadores y confesores al exacto cumplimiento del ministerio. De la página 105 a la 124 se habla de la ciencia necesaria a todo eclesiástico, sobre todo a los que ejercen la cura de almas.

39 Vid, M. Martín Riego, Las conferencias morales, 248-250.

40 Vid, M. Martín Riego, Las conferencias morales, 248-252. 
Además de esta circular Llanes envió a los vicarios foráneos las reglas para dirigir las Conferencias Morales de este Arzobispo.

En la oración fúnebre pronunciada por Antonio Vargas en el Sagrario de la Catedral el 25 de abril de 1795, con motivo de un funeral por la muerte del arzobispo, el canónigo dice así:

“Entre los frutos que el Arzobispo recoge de su visita personal uno es el conocimiento práctico de la necesidad de erigir un Seminario de instrucción tan necesario en esta diócesis. En su ejecución, el arzobispo no descuida la instrucción y reforma de su clero" ${ }^{41}$.

Contamos con el traslado latino que el doctor Pedro Manuel Prieto, canónigo magistral de la catedral de Sevilla, había enviado al arzobispo Llanes y Arguelles en agosto de 1792 para las relationes ad limina. Le indica que su asistencia es condición indispensable para ordenarse y prorrogar las licencias y que obligaban a todos los clérigos, tanto a los ordenados in sacris como a los de menores.

\subsubsection{Digna dotación económica de los curatos: Objetivos y ejecución del Plan de 1791}

Varios son los fines propuestos en el Plan de la erección y dotación de curatos de 1791, figurando entre los más importantes: los económicos, los pastorales y los intelectuales.

\section{a) Objetivos económicos}

Era conocida la pobreza en la que vivía una gran parte del clero parroquial, motivada por la extrema desigualdad en el reparto de las rentas ${ }^{42}$. Existían curatos y beneficios muy bien dotados, contrastando con otros de congruas ridículas. La más grave de estas injusticias era la que afectaba a la remuneración de los curas párrocos, puesto que era la clase que estaba más en contacto con el pueblo ${ }^{43}$.

De esta preferencia por una decente dotación para los párrocos, nació la nueva congrua sinodal para el arzobispado hispalense: 3300 reales anuales para las capellanías, beneficios y curatos que exigían personal de residencia y 1500 reales anuales para los que no la precisaban. Esta última cantidad sería el mínimum para ser admitido a órdenes sagradas.

\section{b) Objetivos pastorales}

El Plan de Curatos pretendía que todo eclesiástico prestase el debido culto y su servicio en la Iglesia donde estuviese fundado su beneficio y ayudasen a los párrocos en la atención pastoral a los fieles. De aquí que dichos beneficios

${ }^{41}$ Vid, M. MARTIN RIEGO, Las conferencias morales, 75.

42 Cfr, J. Matute Gaviria, Anales eclesiásticos y seculares, 115.

43 Cfr, M. Martín Riego, Diezmos eclesiásticos, 56-66. 
simples se convirtieran en residenciales. Los curatos, a partir de esta Plan, dejaron de ser amovibles y manuales, convirtiéndose en perpetuos y colativos ${ }^{44}$.

\section{c) Objetivos intelectuales}

El plan de 1791, significó una gran reforma en las parroquias de la archidiócesis hispalense, ya que todas ellas se proveerán por riguroso concurso ${ }^{45}$.

\section{d) Ejecución del Plan}

Entre las realizaciones del Plan de 1791 destacamos la supresión de 150 beneficios de libre provisión, de los cuales, 84 fueron sometidos a residencia y 28 siguieron en su anterior de libres. Se suprimieron 39 prestameras y algunos pontificales. Los beneficios, prestameras y pontificales, anexos a instituciones, quedaron en su mismo estado. Además, se suprimieron 18 curatos por haber dejado de cumplir las funciones para las que habían sido dotados.

Los curatos fueron divididos en clases para los ascensos: 168 de tercera clase o de ingreso, 82 de segunda clase y 78 de primera clase o término. Todos los curatos quedaron lo suficientemente dotados según sus necesidades. Fueron los beneficios de libre provisión los que aportaron mayor montante en la dotación de los curas. La cantidad total sumada a los curatos arrojó la cifra de 808.264 reales $^{46}$.

La archidiócesis hispalense quedó con 328 párrocos, de ellos 40 en la ciudad de Sevilla y 288 en las otras localidades. La archidiócesis contaba, también con 9 vicarios perpetuos, 1 en la parroquia de Santa Ana de Sevilla y los 8 restantes en Écija, Niebla, Arcos, Puebla de Guzmán, El Coronil, El Puerto de Santa María, Trebujena y Cañete la Real. Además, había 27 tenientes y 84 beneficiados residenciales, quedando 15 de ellos en la ciudad de Sevilla, mientras que los 69 restantes estaban repartidos por las localidades más pobladas del arzobispado.

\subsection{Apertura de la Biblioteca episcopal}

Al arzobispo Llanes se debe la apertura al público, el 12 de abril de 1792, de la Biblioteca del palacio episcopal, que creara el arzobispo Salcedo (17221741 ${ }^{47}$. El arzobispado de Sevilla había deseado que los tribunales eclesiásticos, que se reunían en el palacio arzobispal dispusieran de obras abundantes para facilitarles su consulta. Para ello, Salcedo donó su rica y numerosa librería. Su obra fue continuada por otro arzobispo, el Cardenal Delgado yVenegas

44 Cfr, C. Ros Carvallar, Historia de la Iglesia de Sevilla, 600.

45 Vid, M. MARTín Riego, Los concursos a parroquias en la archidiócesis de Sevilla (1611-1926), Córdoba 1999, 77-80.

46 Cfr, C. Ros Carvallar, Historia de la Iglesia de Sevilla. 601-602.

47 Cfr, M. Martín Riego, «La Sevilla de las Luces», 279. 
(1776-1881). Fue un hombre amante de las letras que, mirando por la prosperidad de la biblioteca, la aumentó considerablemente ${ }^{48}$.

Llanes, que siempre manifestó su simpatía por la ciencia, mostró un vivo interés por favorecer el acceso de los eclesiásticos a la biblioteca del palacio arzobispal, a fin de que tuviesen todos los conocimientos necesarios para el desempeño de los sagrados ministerios. De este modo, además de abrir al público la biblioteca episcopal, la dotó de nuevos volúmenes y la enriqueció considerablemente en todos las ramas del saber humano y con multitud de obras históricas y teológicas, llegándose a un total de 16000 volúmenes. Las obras más destacadas fueron las de derecho canónigo, santos padres, escritores eclesiásticos, Sagradas Escrituras, sermonarios y colecciones de los concilios. Una de las secciones más interesantes de la Biblioteca es aquella dedicada a los libros relacionados con la ciudad de Sevilla y su iglesia ${ }^{49}$.

Casi dos meses después, el seis de junio del año 1792, el prelado recibió de Carlos IV, la Gran Cruz y Collar de oro de la Orden española de Carlos III, por su contribución en la corte y sus compromisos con el mundo intelectual.

\subsection{Actividad benéfica del prelado}

\subsubsection{Limosnas habituales y extraordinarias}

Si un obispo se destacó por su dimensión caritativa, éste fue Llanes y Arguelles $^{50}$. Dada la abundancia de limosnas que el arzobispo Llanes destinaba para cubrir los gastos necesarios ante situaciones de pobreza y de calamidad en sus doce años al frente de la archidiócesis hispalense, tal como viene indicada en los datos reportados por el Archivo General del Arzobispado de Sevilla, nos limitaremos a señalar varias cantidades. Las limosnas podían ser de tipo monetario o podían tratarse de productos agrícolas. De hecho, el arzobispo continuó con la costumbre de sus predecesores de enviar fanegas de trigo a los conventos y de distribuir durante las navidades, en la puerta del palacio arzobispal, hogazas de pan para los más pobres ${ }^{51}$.

También en momentos de malas cosechas e inundaciones, la caridad del prelado se hacía notar. El mes de enero de 1785 comenzó con grandes lluvias, impidiendo que los jornaleros de la villa de Umbrete pudieran acudir a las labores del campo. A ello se sumaba la escasez y carestía del año precedente. Ante esta situación, el 12 de enero de 1785, Llanes envió un escrito al concejo de Umbrete, ofreciéndoles trabajo en determinadas obras del palacio que él tenía en dicha villa ${ }^{52}$.

48 Cfr, F. Aguilar PIñal, Historia de Sevilla en el siglo XVIII, 243.

49 Vid, I.C. Rodríguez Aguilar, Arte y cultura en la prensa: la pintura sevillana 1900-1936, Sevilla 2000, 50-52.

50 Vid, C. LAdERo FERnÁNDEZ - M. MARTIN RIEGO, «Arzobispos y caridad», 40.

51 Cfr, J. Matute Gaviria, Anales eclesiásticos y seculares, 36.

52 Vid, C. Ladero FernándeZ - M. MARTIN RIEGO, «Arzobispos y caridad», 13. 
El 5 de diciembre de 1786, el arzobispo remitió al vicario deVillamartín, una cantidad de 500 reales para socorro de los vecinos de dicha población, ante el gran número de enfermos que experimentaron epidemias tercianas.

El 12 de enero de 1787, se produjo una gran inundación. Más de 122 vecinos del pueblo onubense de San Juan del Puerto, manifestaron a Carlos III la dolorosa situación en que habían quedado. El rey recomienda al arzobispo que ayude a los necesitados. Enterado el arzobispo de la situación en que se encontraba este pueblo, los asistió inmediatamente.

\subsubsection{Legado de un fondo para instituciones benéficas, clérigos pobres y conventos con efecto de 1795 a 1801}

Debido a la amplitud de este legado, nos limitaremos a indicar un ejemplo de estas limosnas por cada año.

Comenzamos por las limosnas dadas a las instituciones benéficas. En 1795, el beaterio de la Trinidad de Sevilla, cuyas constituciones fueron aprobadas por el arzobispo en 1792, recibió 1500 reales. En 1796, la casa de niños Toribios de Sevilla recibió 6000 reales. En 1797, el hospital de Jesús, María y José de Jerez recibió 5436 reales $^{53}$. En 1798 la casa de niños expósitos de Osuna recibió 8000 reales. En 1799 la casa de niños expósitos de Sanlúcar de Barrameda recibió 3000 reales. En 1800, con ocasión de la epidemia que arrasó la ciudad de Sevilla, los huérfanos de los barrios de Triana y los Humeros de Sevilla recibieron 12.000 reales. En 1801, el hospicio de niñas huérfanas de Sanlúcar de Barrameda recibió 6000 reales.

En el periodo comprendido entre 1795 y 1801, los caudales de la vacante del arzobispo se entregaron también a muchos clérigos pobres. Citemos algunos casos.

El 8 de abril de 1795 fueron entregaron 1019 reales y 15 maravedíes a Ambrosio Pérez Morón, cura único de Villanueva de las Cruces, que se le debía por la asignación de 1000 reales que le tenía señalado el prelado difunto. El 12 de abril de 1796 tenemos un libramiento de 188 reales para Manuel Martínez Picazo, diacono de Sanlúcar de Barrameda y residente en Sevilla, a razón de 2 reales diarios. El 17 de julio de 1797 se hizo un libramiento de 1005 reales a favor de José de Aceija, cura de la parroquia de Omnium Sanctorum de la ciudad de Sevilla. Entre estas limosnas aparece la entregada para la comida de los pobres en el jueves santo.

Pero, fueron los conventos los que sellevaron la mejor parte de la distribución de las limosnas de la vacante del arzobispo. La cantidades fueron entregadas a 15 conventos: ocho femeninos y siete masculinos. En 1795, tres días antes de su muerte, Llanes destinó 6000 reales para socorrer las necesidades del Oratorio

53 Vid, M. Martin RieGO, «Limosna y caridad» 415-476. 
de San Felipe Neri. En 1796, el Padre Teodomiro Ignacio Díaz de la Vega ${ }^{54}$, que se hizo cargo de Francisco Javier Cienfuegos y Jovellanos, sobrino de nuestro prelado, recibe 16000 reales $^{55}$. En 1797 el convento de la Merced Descalza de Sevilla recibe 1000 reales. La cantidad más generosa es la de 20.000 reales, librados el 18 de abril de 1798, para el guardián del convento de los Capuchinos de Sevilla, a fin de costear el arreglo de la bóveda de la capilla mayor.

\subsection{Visita Pastoral a las parroquias: el estilo personal de Llanes}

Acompañado por algunos misioneros, el prelado se propuso realizar dos grandes visitas pastorales por todo el arzobispado, en las que constató las dificultades de esta gran empresa misional y observó que existían muchos asuntos de interés que le llamaban la atención y que le exigían su residencia permanente en la archidiócesis. Generalmente, era el mismo arzobispo quien hacía personalmente las visitas. Pero, en ciertos momentos delegaba esta función en Fray Diego José de Cádiz, llegándolo a nombrar visitador general del arzobispado ${ }^{56}$.

Uno de los familiares de Llanes dio fe de la atención desmedida que el arzobispo otorgaba a la visita pastoral al decir lo siguiente:

“¿Y cuántas veces se levantó por la mañana, a pesar de su quebrantada salud, para disponerse con la oración mental a celebrar el augusto sacrificio de la misa, administrar seguidamente el santo sacramento de la confirmación, y emprender después largas jornadas por caminos fragosos e intransitables? Una vez, sin haber tomado un ligero desayuno, se salvó milagrosamente de caer del caballo que le llevaba a sus tareas. Si no fuese por uno de los familiares que el acompañaban, hubiera acabado sin vida. Fue muy raro el pueblo en que su Excelencia no hizo una plática a los fieles antes de visitar los Sagrarios, exhortándolos a que se apartasen de los vicios, y siguiesen las virtudes. Al clero le exhortaba en privado.Y, últimamente, ante situaciones de excesos, remediaba todo aquello que estaba en sus facultades, para aplicarlo inmediatamente. ¿Puede exigirse más, en comprobación del celo pastoral del Señor Llanes?" 57 .

\subsection{Promoción de las misiones populares}

Llanes dispuso que se hicieran dos misiones, según lo refieren los Anales eclesiásticos, tal como así viene indicado por Alonso Morgado ${ }^{58}$. Por medio de las misiones populares, el virtuoso prelado empleaba cuantos medios estaban

54 Vid, M. Martín Riego - J. Roda Peñas, El Oratorio de San Felipe Neri de Sevilla. Historia y Patrimonio artístico (1698-1893), Córdoba (2004), 483-546.

55 Vid, M. MARTín Riego, «El oratorio de San Felipe Neri de Sevilla (1698-1893)» en Isidorianum 14 (1998) 500-517.

56 Cfr, J. Alonso Morgado, Prelados sevillanos, 706.

57 Cfr, J. Alonso Morgado, Prelados sevillanos, 704.

58 Cfr, J. Matute Gaviria, Anales eclesiásticos y seculares, 167. 
a su alcance para conseguir la santificación de las almas. Para emprender esta tarea, el arzobispo se sirvió de la ayuda del ya mencionado, fray Diego José de Cádiz ${ }^{59}$.

\subsection{Acogida de clérigos franceses «no juramentados» (1792-1794)}

Los Anales refieren, cómo a consecuencia del Decreto que promulgó la Convención nacional francesa el 26 de agosto de 1792, en la que se dictaminó que todos los clérigos que no quisieran hacer el juramento de la Constitución civil del clero en el año 1791, saliesen de aquel reino en el término de quince días, brilló aún más la liberalidad de Mons. Llanes, pues dio acogida a cuantos se dirigieron a la archidiócesis.

Del 2 al 4 de septiembre de 1792, fueron matados más de 300 sacerdotes, entre ellos tres obispos. Durante los meses siguientes fueron expulsados de Francia más de 30.000 eclesiásticos ${ }^{60}$. A partir de ese momento, muchos de ellos se vieron obligados a salir de su país.

Unos 6000 clérigos habían llegado a España, 5888 del clero secular y 434 religiosos, y estaban repartidos entre 58 diócesis.

A la archidiócesis de Sevilla, empezaron a llegar en masa a partir de septiembre de 1792. Según las investigaciones de Avellá Chafer, en enero de 1792 ya habían llegado cinco a Écija ${ }^{61}$. Movido por la solicitud del Estado y el afecto que le tenía a la Iglesia y a sus fueros, Llanes no escatimaría medios para mejorar la estancia de aquellos eclesiásticos, quienes desde 1792 hasta 1794, fueron llegando a Sevilla ${ }^{62}$. José Rodríguez Borja, vicario foráneo de la ciudad astigitana, acogió en dos conventos a algunos de estos clérigos, informando al arzobispo de sus necesidades. Su número fue en aumento hasta $1794^{63}$.

El arzobispo escribió dos circulares dirigidas a los superiores de comunidades religiosas masculinas: la primera, el 23 de febrero de 1793 y la segunda, el 23 de abril de 1793. En el archivo diocesano se conservan cuarenta y cinco respuestas a ambas circulares, cuyas fechas oscilan entre el 15 de mayo y el 30 de junio de 1793.

A finales de 1794, fueron acogidos ciento cuarenta y un clérigos, diecinueve regulares, una religiosa y un niño de diez años. La cifra de clérigos franceses acogidos en Sevilla, según otros autores, podría elevarse a 160, provenientes de la mayor parte de las diócesis del sur de Francia, sobre todo de Toulouse.

59 Vid, J. Matute Gaviria, Anales eclesiásticos y seculares, 170-175.

60 Vid, A. Roger, «La Iglesia católica y la Revolución», en J. Hubert (dir.), Manual de Historia de la Iglesia, VII, Barcelona 1978, 77-84.

61 Vid, F. Avellar CHAFER, «El clero francés emigrado en Sevilla durante la Revolución 1792-1801» en Archivo Hispalense 141 (1967) 101-146.

62 Vid, C. LADERO FERNÁNDEZ - M. MARTIN RIEGO, «Arzobispos y caridad», 33.

63 Vid, M. Giacomo, La Chiesa nell'età del liberalismo, Brescia 1980, 7-26. 
El arzobispo tuvo que correr con la manutención de la mayor parte de estos clérigos, dando una peseta diaria a cada uno de ellos. Las comunidades religiosas, siguiendo el ejemplo del generoso prelado, les abrieron sus casas, en las que se contabilizaron un gran número de clérigos albergados. Y lo mismo hicieron otros particulares anónimos de buena voluntad, ofreciendo sus respectivas casas. Tenemos constancia de esta generosidad de algunos conventos gracias a una carta de Llanes, con fecha del 6 de diciembre de 1794, dirigida al cardenal Lorenzana, arzobispo de Toledo.

Tras la muerte del arzobispo, gran parte de los caudales de sus espolios fueron destinados a los eclesiásticos franceses residentes en la archidiócesis hispalense. Según la documentación conservada en el archivo diocesano, de los caudales de la vacante de Llanes se pagó a los emigrados en 1795, la cantidad de 45.344 reales y en 1796 la suma de 23.112 reales $^{64}$.

En este mismo año de 1795, eran pocos los franceses que residían en la archidiócesis. En concreto, el 27 de febrero de 1795, se enviaron 300 reales a Juan Laclaverte y José Luis Sauvage, sacerdotes franceses que residían en La Campana. Y el 19 de mayo se enviaron 4404 reales a José Guerrero de Ahumada, vicario foráneo de Marchena, para los alimentos de los sacerdotes franceses que residían en ese pueblo de Sevilla. El 31 de mayo se remitieron 2340 reales a José Rodríguez Borja, vicario foráneo de Écija, por haber suplido los gastos de los clérigos franceses que habían residido en dicha ciudad y el 1 de julio de 1796 se enviaron 5284 reales a Juan Verger Ramírez, vicario foráneo de Carmona, para los clérigos emigrados franceses que residieron en dicha localidad.

En 1795 se entregó la cantidad de 8651 reales, procedentes de los espolios del arzobispo, distribuidos de la siguiente manera: 1100 al convento de San Agustín de Sevilla, a base de 4 reales diarios por cada uno de los tres clérigos emigrados franceses; 5084 reales a varios conventos para la misma intención; 124 reales al convento de los trinitarios calzados de Sevilla para un clérigo francés que residió en dicha comunidad el mes de diciembre de 1794; 1500 reales al convento de San Agustín de Osuna; 843 reales a los carmelitas de Aracena por los alimentos del clérigo francés Domingo Duboise.

En la oración fúnebre de Antonio Vargas, el canónigo nos habla de la caridad del difunto prelado con los emigrados: "Sacerdotes emigrados de Francia, decid vosotros los oficios grandes de caridad que os hizo nuestro prelado difunto" ${ }^{\prime 65}$.

Nada tiene de extraño que los sacerdotes emigrados franceses que todavía permanecían en Sevilla en 1795, celebraran un funeral en la parroquia del Sagrario el 19 de abril de 1795, por el alma del arzobispo, en gratitud por la

64 Vid, M. MarTín RieGo, «La Sevilla de las Luces», 250-255.

65 Cfr, A. VARGas, Oración fúnebre que en las exequias que hicieron por el Excm. Señor Don Alonso Marcos de Llanes y Arguelles, arzobispo de Sevilla, el día 28 de abril de 1795, Sevilla 1795, 20-22. 
generosidad que tuvo con ellos. Cuando la situación se normalizó en Francia, la mayoría de ellos, volvieron en los años sucesivos a tierras galas, pero les quedó el grato recuerdo de la acogida del arzobispo y de la gente de Sevilla ${ }^{66}$.

\subsection{Reconocimiento de Llanes por la Universidad de Sevilla}

La universidad de Sevilla acordó ofrecer al arzobispo Llanes las borlas de doctor en filosofía, leyes, cánones y teología, a título honorífico, por los servicios prestados a esta institución académica, a la ciudad y a la Corona, al igual que ocurriría con su sucesor, el arzobispo Despuig, cuatro años más tarde ${ }^{67}$. Este ofrecimiento se hizo efectivo el 3 de enero de 1793, por medio de una diputación compuesta por el Rector, el Decano de la Universidad y un individuo de cada claustro.

Después de hablar personalmente con el rector y de entregar sus respectivas esquelas a los invitados, el arzobispo invitó a un banquete a la diputación universitaria y dio orden para que su mayordomo pagase todos los gastos. Regaló a la universidad una escribanía de plata y se hizo cargos de los gastos de los estudiantes que se habían distinguido de forma brillante en sus carreras y que no podían pagar sus estudios por sus propios medios.

Esta concesión que hizo la universidad al arzobispo se llevó a cabo por medio de una manifestación pública teatral, erigida en el patio de la misma universidad y que fue desarrollada por los mismos estudiantes. En ella se representaba la tragedia volteriana de la Zaida ${ }^{68}$. La pieza teatral recibió aclamaciones por parte del prelado, de los cabildos eclesiástico y secular y de determinadas corporaciones del mundo de la nobleza sevillana que participaron en este evento.

\subsection{Muerte de Llanes y honras fúnebres}

Al término de su segunda Visita Pastoral por todo el arzobispado, avanzaron los problemas de salud de nuestro arzobispo, a causa de problemas asmáticos. El dos de enero de 1795, su confesor le administró el Sagrado Viático y la Extremaunción. Nada más pronunciar los nombres del patriarca San José y de la Virgen, murió el siete de enero de 1795, a los 62 años.

Después de anunciarse su fallecimiento, sus funerales se celebraron, según los describen los Anales eclesiásticos ${ }^{69}$. Como se indica en la documentación

66 Vid, C. Ladero Fernández - M. Martín Riego, «Arzobispos y caridad», 46.

67 Cfr, Q. Aldea Vaquero - T. Marín Martínez - J.Vives Gatell, Diccionario de historia eclesiástica de España, Madrid 1972, 252.

68 Vid, J. Guillén TorralBa, «Inicios teológicos e intelectuales de Blanco White (1775-1800)» en Índice Minervae Baeticae 30 (2002) 275-278.

69 Vid, J. Matute Gaviria, Anales eclesiásticos y seculares, 245-250. 
conservada en el Archivo General del Arzobispado de Sevilla, el 2 de marzo de 1795, el cabildo eclesiástico, agradecido por los beneficios recibidos del prelado, se hizo cargo de los gastos del funeral De Mons. Llanes. Sus honras fúnebres continuaron hasta seis meses después de su fallecimiento.

El 28 de marzo de 1795, el maestresala de la catedral ofició una misa por el eterno descanso del prelado. El 26 de abril se celebró otra misa en sufragio por su alma en la iglesia parroquial de San Pedro, que solía ser frecuentada por el difunto arzobispo. Tres días más tarde, los familiares manifestaron su gratitud al arzobispo, en una misa celebrada en la Iglesia del Sagrario de la Catedral.

Esta misa fue recordada, especialmente, por la participación de personalidades destacadas como la de su obispo auxiliar, Agustín de Ayesterán y Landa, la de los arcedianos de Écija y de Sevilla y las del deán de la catedral y dos canónigos. Uno de estos dos canónigos, el ya mencionado Antonio de Vargas, fue el encargado de hacer la oración fúnebre. En ella, el canónigo alaba la labor desarrollada por el arzobispo Llanes y Arguelles de cara a la mejora económica, intelectual y moral del clero:

“No olvidéis a un prelado que os lo proporciona y promueve en este plan de oro de erección y dotación de curatos propios y colativos, que trabaja, que concluye y perfecciona a pesar de mil obstáculos que vence y supera. Hablaría ahora de las conferencias morales tan recomendadas en los Sínodos, para tan olvidadas en el Arzobispado, que él restablece prescribiendo el modo de tenerlas con fruto y aprovechamiento" ${ }^{\prime \prime 7}$.

Fue tan sentida la muerte de Llanes, que el cabildo le erigió un sepulcro bajo el altar mayor de la parroquia del Sagrario de la catedral. Mons. Llanes fue el único de los prelados sevillanos de la segunda mitad del siglo XVIII que recibió sepultura en tierra sevillana. Este sepulcro fue concluido a finales de agosto de 1798 y consta de un frontispicio compuesto por Pedro Manuel Prieto, canónigo de la Santa Iglesia Catedral.

\section{LAS EMPRESAS ARTÍSTICAS DE LLANES COMO ARZOBISPO DE SEVILLA}

Durante la etapa de Llanes como arzobispo de Sevilla, se ponen de manifiesto numerosas iniciativas en el terreno de la arquitectura, la escultura y la pintura que, por otra parte aportan interesantes noticias sobre algunos artistas sevillanos de las dos últimas décadas del siglo XVIII ${ }^{71}$. En el palacio arzobispal de Sevilla se conserva un retrato del arzobispo realizado en el año 1793 por el

Cfr, J. Matute Gaviria, Anales eclesiásticos y seculares, 150.

71 Vid, F. Amores MartíneZ, «Las empresas artísticas del arzobispo ilustrado D. Alonso de Llanes y Arguelles (1783-1795)» en Laboratorio de arte 13 (2000) 173-192. 
pintor y dorador José Suárez, para ser colocado en la biblioteca que el arzobispo abrió al público el año anterior ${ }^{72}$.

Se trata de una obra de interés $(1,71 \times 1,41 \mathrm{~m}$.), en la que aparece el prelado a la edad de 61 años, sentado en un sillón, representado de cuerpo entero y mirando hacia la derecha, junto a una mesa en la figuran varios libros. El personaje apoya el brazo izquierdo sobre el asiento, mientras que con el derecho sostiene un libro entreabierto. Aparece revestido con el hábito episcopal, luciendo en el pecho la Gran Cruz de la Orden de Carlos III. En el ángulo superior derecho aparece pintado su escudo de armas, escasamente visible debido a la capa de polvo que recubre el lienzo. Lo mejor de la pintura es el tratamiento del rostro, de sereno naturalismo que deja traslucir una personalidad profunda de forma nada efectista.

El profesor Valdivieso afirma que esta obra puede ser considerada como la de un retratista de oficio, basándose en las escasas obras que hasta ahora se conocían de su mano. Precisamente, el mayor interés de este retrato radica en la posibilidad de compararla con otras obras del artista.

En los últimos años se han hallado nuevos datos sobre su trayectoria profesional. En 1775 José Suárez se encontraba matriculado en la escuela de las Tres Nobles Artes, y aparece por primera vez en 1781 como oficial ayudante de Juan de Espinal en la realización de las pinturas murales que decoran la escalera principal del palacio arzobispal de Sevilla.

Recientemente, se ha documentado quizá el dato más relevante, el de que al menos desde 1789 ocupó el cargo de maestro mayor de pintor y dorador del arzobispado, a las órdenes de Alonso de Llanes. Hasta fechas muy recientes, los historiadores del arte, solo habían reparado en la faceta de retratista de Suárez, ya que de su mano se conservan dos interesantes retratos de Don Juan de Saavedra y su esposa, cuya calidad es tal que llegaron a ser atribuidos al círculo de Goya.

El aspecto, quizás, más novedoso e interesante de las iniciativas artísticas emprendidas por Llanes y Arguelles, corresponde a las más importantes reformas que el prelado llevó a cabo en el palacio arzobispal de Umbrete, residencia temporal de los arzobispos sevillanos ${ }^{73}$.

Estas obras de reforma se llevaron a cabo en cuatro fases principales, desarrollándose la primera de ellas entre los años 1788 y 1789, corriendo a cargo de Francisco del Valle, maestro de carpintería del arzobispado. En esta primera fase se procede a la construcción de un oratorio y cuarto de sacristía, el cerramiento de la galería que daba a los jardines en la parte norte del edificio y la construcción de otras habitaciones en la planta baja.

En una segunda fase, desarrollada entre los meses de agosto de $1790 \mathrm{y}$ noviembre de 1791, las obras se centraron en la planta alta, con la terminación de su galería principal, la construcción y la reparación de la escalera.

72 Cfr, E. VAldivieso GonzÁlez, y M Masé HerrerA, «Catálogo de las pinturas del palacio arzobispal de Sevilla», en Laboratorio de arte 10 (1979) 99.

73 Cfr, E.VAldivieso González, y Ma José Herrera, Historia de la pintura sevillana, Sevilla 1992, 349. 
A finales de 1791, se inició la tercera fase, en la que se labró la nueva portada, terminada en noviembre de 1792, con el escudo de armas del prelado y un balcón de hierro. Las obras en el palacio de Umbrete continuaron hasta el fallecimiento del arzobispo, con la construcción de la cocina, en el año 1793.

Teniendo en cuenta que Alonso de Llanes deseaba pasar largas temporadas en el palacio de Umbrete, vio la necesidad de construir un retablo en 1788, con el tema de La imposición de la casulla de San Ildefonso. La elección de este tema venía determinada por el hecho de que se trataba de la iconografía más tradicional del santo patrono del arzobispo.

Es conocido el patrocinio del arzobispo sobre las obras de reforma que durante 1789 y 1790 se llevaron a cabo en la iglesia del convento sevillano del Espíritu Santo, que según el profesor Morgado fue bendecida por el prelado el 23 de enero de 1791. El arzobispo mandó pintar un lienzo, que se conserva sobre la verja del coro de esta misma iglesia, con el tema de Pablo III concediendo la Bula de fundación a las religiosas del Espíritu Santo. Se trata de una obra de correcta ejecución que aparece firmada por Francisco Ximénez (1717-1793), artista que fue uno de los fundadores de la escuela de las Tres Nobles Artes y de la que fue su director desde 1785.

También, Mons. Llanes encargó las obras del retablo de esta iglesia a Suárez, pues este artista declaraba en febrero de 1791,"estar haciendo un retablo para el excelentísimo señor Arzobispo"74.

Otro convento de monjas, el de las dominicas de Santa María la Real, situado en la calle de San Vicente de Sevilla, fue objeto de la munificencia del arzobispo, ya que en él, en junio de 1792, Alonso de Llanes emprendió la obra del retablo mayor.

El prelado contribuyó con sus cuantiosas rentas a la construcción de otros edificios, como es el caso de la capilla del Beaterio de San Antonio, que se empezó a mediados de 1791 y concluyó a principios de 1793. Además, ayudó a reformar los Beaterios de la Trinidad y del Pozo Santo, la iglesia de San Marcos o el convento de las Capuchinas.

Por su parte, en las obras de la catedral de Sevilla, concluidas en 1793, el prelado aportó unos sesenta mil pesos, destinados concretamente, a las obras de restauración de las puertas de la Catedral y a la construcción de la capilla de San José, donde Alonso de Llanes recibió sepultura.

Era tal la cantidad de gastos que corrían a cuentas de la mesa arzobispal hispalense, que se llegó a pensar que, una de las causas por las que los feligreses temían que la sede quedara vacante era por la escasez de limosnas. Y, es que en más de una ocasión, las arcas de la mesa arzobispal quedaron vacías por gastos en obras de artes y limosnas ${ }^{75}$.

74 Vid, F. Ros González, «Los modelos de retablos del arzobispo sevillano Alonso Marcos de Llanes y Arguelles» en J. PANIAgua Pérez, España y América entre el Barroco y la Ilustración (17221804). II Centenario de la muerte del Cardenal Lorenzana (1804-2004), León 2005, 591-606.

75 Cfr, A. Domínguez Ortiz, Sociedad y mentalidad en la Sevilla del Antiguo Régimen, Sevilla 1979, 93-94. 


\section{APÉNDICE DOCUMENTAL}

\section{Exhortación Pastoral con ocasión del Jubileo del Año Santo de 1776}

No habíamos pensado, amados hermanos, y Fieles míos, molestar vuestra atención con exhortaciones, ni Cartas Pastorales, hasta recorrer y visitar nuestra Diócesis, contentándonos entre tanto con excitar vuestro celo, y cumplimiento de vuestras respectivas obligaciones, y atender a vuestras necesidades, al mismo tiempo que íbamos visitando vuestras iglesias, y Pueblos; y aunque en todo seamos deudores los Prelados a promover la salvación de las almas, ninguno nos parece más oportuno que el presente, en que nuestro Santísimo Padre Pío VI, como fiel dispensador de los tesoros de la Iglesia, temblando con el peso del ministerio universal, que tan felizmente se le confió, en ocasión de estar publicado en Roma el jubileo del año Santo, nos mira como Padre amoroso, concediendo las mismas indulgencias, y Gracias a todo el Orbe Católico.

Y para que las recibáis con utilidad, y provecho de vuestras almas, no hallamos palabras más propias que las del apóstol San Pablo, quando predicaba a los de Corinto no recibiesen en vano la gracia del Señor, y general de su conversión en un tiempo, y días de salud, en que el gran Padre de las misericordias ofrecía a su Hijo encarnado la vocación de las gentes, copiosas lluvias de gracia, y la reconciliación del Género Humano ${ }^{76}$.

\section{Carta Pastoral de despedida como obispo de Segovia}

Esta consideración me hace menor el desconsuelo al separarme y despedirme de aquellos miembros con quienes componía un cuerpo mystico en lo espiritual de esta Diócesis, y sí me aflige el temor, que habiéndose servido S. M. (Dios le guarde) nombrarme para la iglesia y arzobispado de Sevilla, tanto mayor que mis méritos y tan superior a mis fuerzas, ¿cómo podré imitar, ni menos desempeñar un ministerio y cargo que miraban como insoportable los Leandros, los Isidoros y otros santos prelados? Porque, ¿qué virtud, que instrucción ni qué zelo es el mío? Pero no siendo justo que un vasallo tan obligado deje de seguir las insinuaciones de su señor natural, y tan digno de ser obedecido como nuestros católicos y piadosísimo rey y confiando, en que la Divina Providencia no desampara con sus luces a quien de verdad y con humildad las solicita, cautivé mi entendimiento y sujeté mi voluntad a la de Dios y nuestro soberano.

Pero la flaqueza, miseria y condescendencia junto con mi ignorancia malograban mis buenos deseos: defecto es de nuestra naturaleza no atinar con

76 A.M. De Llanes y ARGÜelLes, «Exhortación pastoral que el Ilustrísimo Señor D. Alonso Marcos de Llanes y Arguelles, obispo de Segovia, hace a los vicarios, curas parrocos, confesores, predicadores, y demás fieles de su obispado, con motivo de la extensión del jubileo del Año Santo: concedida por nuestro Santisimo Padre el Señor Pio VI a todo el Orbe Christiano», J. YbarRa (ed.), Bib. S.XVIII, V, Madrid 1776, n. 2719. 
las acciones (...) Me hace temblar y llega al alma aquella terrible sentencia del espíritu Santo: hay camino que parece al hombre justo, más su fines le precipitan, y le llevan a la muerte (...) Si consideramos las obligaciones de un obispo, veremos en cada una de ellas infinidad de tropiezos y contradicciones para su execución y no es menor la que se gradúa por costumbre y se autoriza con los dictámenes de hombres al parecer sabios y justos a los ojos del mundo (...)

Esto es lo que contrista a los prelados y hace pesadísima la carga del oficio pastoral, porque con el olvido que se experimenta de las leyes, si se renueva y se procura su observancia, se reputan novedades, queriendo dar valor a las que se llaman costumbres, siendo contrarias a las mismas reglas establecidas por la Iglesia quando ésta reprueba todo lo que se opone a sus sagradas máximas y destruye el nervio de la disciplina (...) Lo licencioso de las costumbres públicas es la causa de las venganzas del cielo y para desarmarla es tenerla es menester que todos nos renovemos en la religión y piedad por medio de un sincero arrepentimiento $^{77}$.

\section{Plan de Erección y Dotación de Curatos del año 1791}

En el cómputo de la congruas, así de Curatos como de Beneficios, no sólo se consideran los frutos ciertos de Diezmos, sino también los inciertos y eventuales del servicio, y demás emolumentos, dotaciones fijas y funciones parroquiales, que se entienden bajo el nombre de pie de altar, y este producto se debe rebajar en los Beneficios libres de residencia para liquidar su legítimo valor ${ }^{78}$.

Habiéndose introducido en algunas iglesias el intolerable abuso de haberse hecho Beneficios simples los Curatos, encargando sus poseedores la cura de almas a un Teniente, contra la naturaleza y estrecha obligación de los Curatos en su origen, y en conocido perjuicio de los feligreses, que carecen de lo puntual y mejor asistencia a que son acreedores, y lograrían con el propio Párroco, como también de las limosnas que expendería, y no puede hacer el Teniente por la escasez de sus emolumentos; entiende la Cámara, será muy justo y conveniente, que el Prelado proponga en su plan la erección de Curatos, reintegrando en la cura de almas los Beneficios que de esta naturaleza hubiera en su diócesis ${ }^{79}$.

Exigimos los Curatos en colativos, y en Beneficios curados perpetuos, sujetos a concurso desde primera vacante, y a precisa personal y continua residencia de los poseedores en las respectivas Iglesias para el mejor cumplimiento, conforme a lo dispuesto por el Santo Concilio de Trento, y Bulas Pontificias.

Con el objeto de promover y conservar la instrucción del clero, se hallan establecidas en este Arzobispado las conferencias morales, y dispuesta su rigurosa

A.M. Llanes y Arguelles, Pastoral del ilustrísimo señor Don Alonso Marcos de Llanes, 18-30.

78 A.M. Llanes y Argüelles, Plan y Decreto de Erección y Dotación de Curatos del Arzobispado de Sevilla, Sevilla 1791, 8.

79 A.M. Llanes y ArgüElles, Plan y decreto, 5. 
observancia, a las que deberán asistir indistintamente los Curas, Beneficiados, Capellanes y Clérigos de mayores y menores órdenes, con arreglo a lo prevenido por nuestra instrucción expedida con carta circular de cuatro de marzo del año pasado, de mil setecientos ochenta y cinco, no admitiendo a ninguno a dichas órdenes, ni a las licencias de celebrar, confesar y predicar, o a sus prórrogas, sin que acredite haber asistido con fruto ${ }^{80}$.

80 A.M. Llanes y Argüelles, Plan y decreto, 20. 